\title{
ANALYSIS OF THE RESULTS OF ACOUSTIC EMISSION DIAGNOSTICS OF A STRUCTURE DURING HELICOPTER FATIGUE TESTS
}

\author{
Aleksandrs URBAHS ${ }^{1}$, Kristine CARJOVA ${ }^{2}$, Jurijs FESCUKS ${ }^{3}$ \\ Institute of Aeronautics, Riga Technical University, Kalku 1, LV-1658 Riga, Latvia

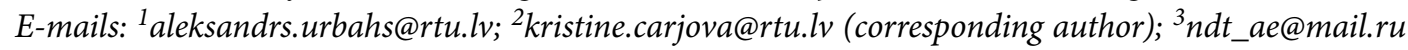

Received 26 April 2016; accepted 23 May 2017

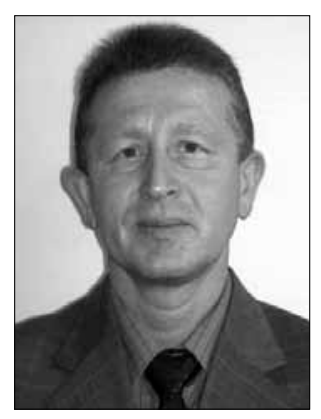

Aleksandrs URBAHS graduated from the Faculty of Mechanical Engineering, Riga Civil Aviation Engineering Institute in 1981. In 1986 he was awarded a Dr.sc.ing. degree by the same faculty. In 1997 he was awarded a Dr habil. sc. ing. degree by Riga Aviation University. In the period from 1989 to 1999 - Vice Dean and Dean of the Faculty of Mechanical Engineering, Riga Aviation University. Since 1999 - full-time Professor at Riga Technical University. In the period from 1999 to 2012 - Head of the Institute of Transport Vehicle Technologies at Riga Technical University. Since 2012 - Head of the Institute of Aeronautics at Riga Technical University. He holds more than 20 patents and has published more than 320 scientific papers.

His fields of research: aeronautics, nanomaterials, non-destructive testing, structural materials, unmanned vehicles, transport systems and logistics.

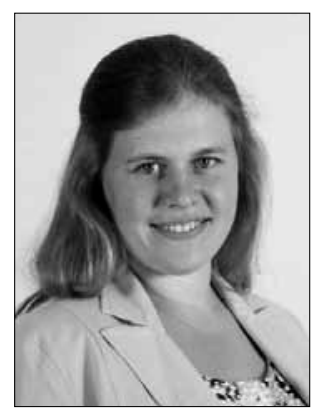

Kristine CARJOVA graduated from the Faculty of Mechanical Engineering, Transport and Aeronautics, Riga Technical University in 2016 and received a Dr sc. ing. degree. In 2010 she obtained a degree of Master of Science at the Latvian Maritime Academy. She graduated from Latvian Maritime Academy and obtained a Specialisation of Engineer-Ship Navigator. Work experience: 2004 to 2007 - Navigator of Merchant Vessel. 2009 to 2011 - Captain on ASD tugboat at JSC PKL Flote. Since August 2011 - Researcher at the Institute of Aeronautics, Riga Technical University. Since 2017 she is a head of Aircraft Theory and Structure department. Her fields of research: aeronautics, non-destructive testing, structural materials, unmanned vehicles.

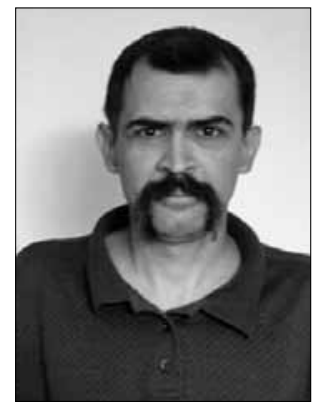

Jurijs FESCUKS has been a Doctoral Student at the Institute of Aeronautics, Riga Technical University since 2012. He has been awarded Msc. eng in 2016 at the Institute of Aeronautics, Riga Technical University.

His fields of research: material fatigue, fatigue cracks, acoustic emission, ultimate loads and strain, fatigue mathematical models.

Abstract. The study is devoted to a perspective diagnostic method, which makes it possible to deal with diagnostic tasks - the acoustic non-destructive inspection method based on acoustic emission (AE) signal parameter analysis. The practical use of this method is related to the interpretation of diagnostic measurement data. The parameters of acoustic emission (AE) signals were measured during bench tests of the tail boom structure and fin, as well as the joint areas of the fin, tail boom, and fuselage of the helicopter (joint area No.1 and No.19, frames of the tail boom and fuselage respectively). The analysis of fatigue damage kinetics was carried out in several stages for groups of bolts and for characteristic structure loading intervals. Bolt fracture was predicted at least 26 to 44 flight hours before the actual 
collapse. Using the AE parameters, the micro crack origin intervals identified when the bolt bearing capacity after the occurrence of the damage reached $96 \%$.

Keywords: acoustic emission, helicopter structure, fatigue defects, bolts, fractographic research.

\section{Introduction}

Aviation structure failures are mostly related to fatigue damage accumulation and fatigue crack development (Lingelli 2009; Shanyavskiy 2003). Therefore, one of the most important issues in assessing fatigue is the development of scientifically based methods for fatigue damage evaluation and longevity calculation of structural elements in variable voltage conditions. Using such methods, it is possible to choose the optimum shape and size of the design at the design stage and to control the real process of damage accumulation in structures during exploitation.

Regarding structure load-bearing capacity, when a large part of its resource construction material is being operated with defects, but the exploitation time is determined by defect development time until its critical dimensions, methods that make possible to detect the defects at an early stage and to predict the resources of the remaining structure with cracks become actual.

A perspective diagnostic method which makes it possible to deal with such a task type is the acoustic non-destructive inspection method based on acoustic emission (AE) signal parameter analysis (Urbahs et al. 2012 , 2015). The practical use of this method is related to the interpretation of the diagnostic measurement data.

\section{Helicopter bench test and the experiment methodology}

A helicopter test bench (Fig.1) was used to develop a defect localization methodology for helicopter structure fatigue damage technical diagnostics. The controlled structures and parts for the test object were:

1. Helicopter tail boom;

2. Helicopter keel.

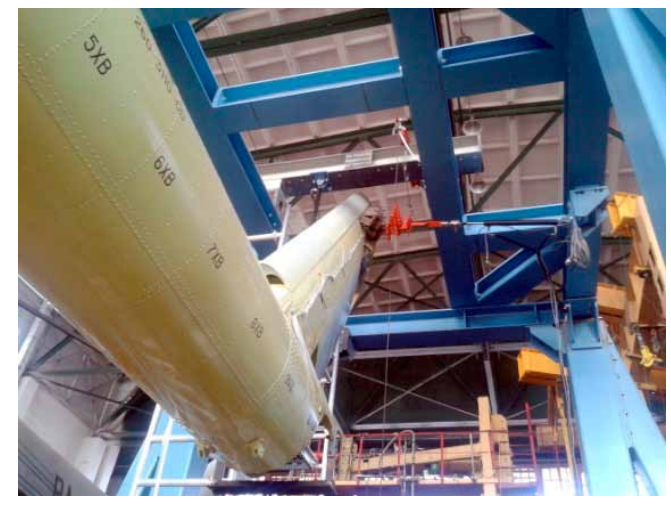

Fig. 1. Applied distribution load on the keel of a real structure (view against flight direction from the left side)
Load values in the fatigue test program were set based on stress-strain state measurements of a helicopter sample during flight trials (Aviatest 2014). The load is applied at the rotor bush $-P_{x}^{H} P_{y}^{H} P_{z}^{H}$, at the fastening points of stabilizator $-P_{y}$, and at the keel $-P_{z}^{k}$.

The frequencies of applied loads are $f_{\text {test }} \geq 0,017-0,1 \mathrm{~Hz}(T=10-60 \mathrm{sec})$.

A visual inspection of the object was carried out after every 400 to 1000 loading cycles. In the tail boom and keel, the most critical points from the fatigue strength point of view are the following areas:

a) joint of tail boom and central fuselage part (Fig. 2);

b) tail boom frames No. 1 and No. 2 (from the inside and outside);

c) area between tail boom frames No. 1 and No. 3;

d) joint of tail boom and keel.

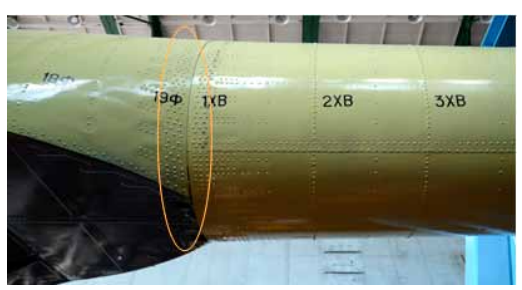

Fig. 2. Joint of tail boom and central fuselage part

According to resource estimation using the Palmgren-Mainer rule (Paramonov 2009), taking into account the factor of spoilage, in linear summation hypothesis $\eta_{\hat{O}}=2$, we obtain that 48 load cycles under the test conditions have to be carried out to obtain a onehour flight resource.

Acoustic emission R15a type sensors were installed on the skin of the tail boom and the keel from the outside (Fig. 3).

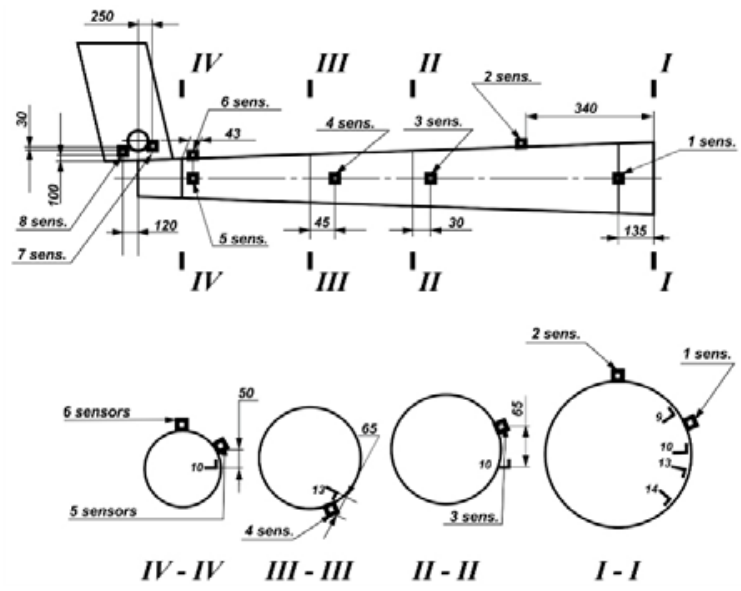

Fig. 3. Location of AE sensors on the tail boom and keel 


\section{General information on the test results}

The parameters of acoustic emission (AE) signals were measured (Vallen 2006) during bench tests of the tail boom structure and fin as well as the joint areas of the fin, the tail boom and fuselage of the helicopter (joint area No.1 and No. 19, frames of the tail boom and fuselage respectively).

The tests revealed the following defects, the propagation of which was being monitored with the help of the AE method from the moment they appeared, up to their crucial growth, and/or up to the failure of the structural components (Fig. 4):

- fracture of bolts No. 18-1, No. 19-1 and crack detection in the material of bolt No. 21, in 23022 load cycles;

- fracture of bolts No. 18-2 and No. 19-2, in 51000 load cycles;

- fracture of bolt No. 14 and crack detection in the material of bolt No. 13, in 69603 load cycles;

- fracture of bolt No. 15, in 78601 load cycles;

- fracture of bolt No. 19-3, in 80615 load cycles;

- fracture of bolt No. 18-3, in 98175 load cycles.

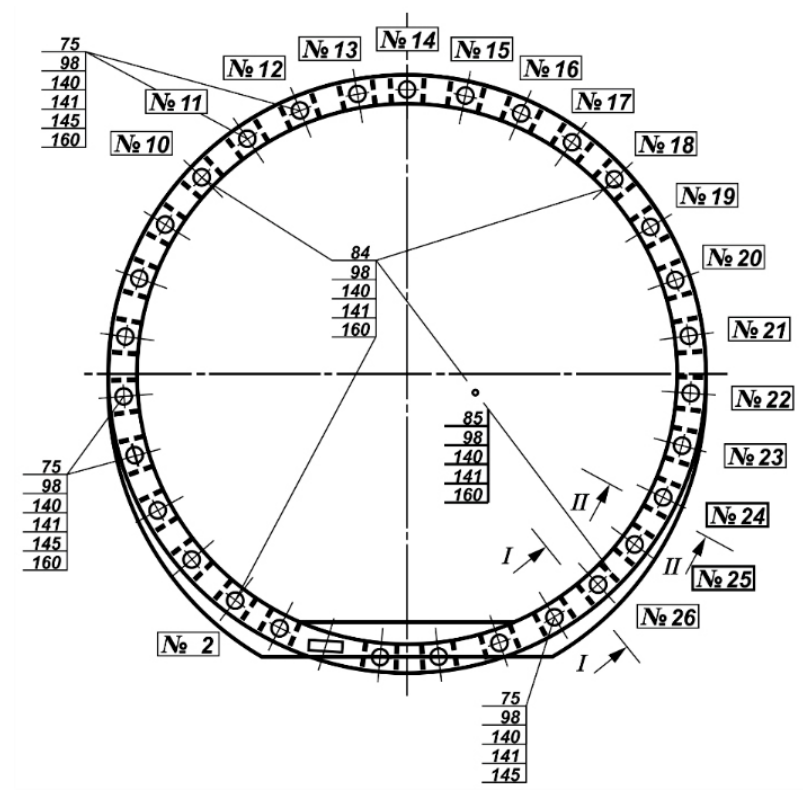

Fig. 4. Joint bolts of tail boom frame No. 1 and fuselage in the flight direction (cross sections are depicted in Fig. 5)

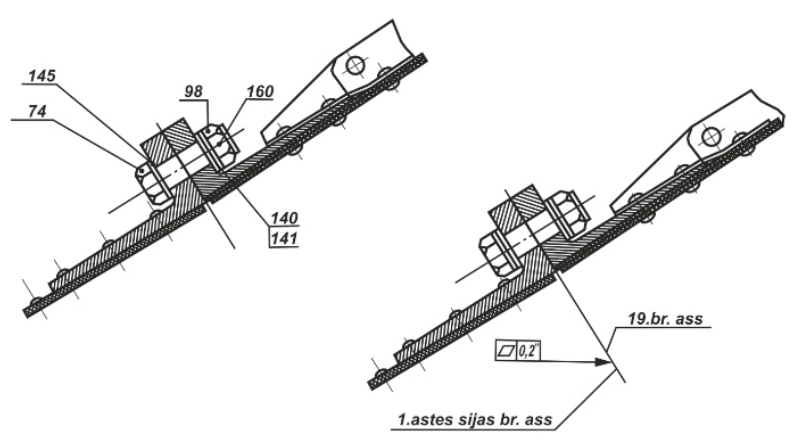

Fig. 5. Cross sections of tail boom frame No.1 in joints
4. Overall evaluation of the informational content of AE signal diagnostic parameters

On the basis of the analysis of AE parameters recorded in the process of testing, the following was revealed. The AE signal amplitude recorded for all channels quantitatively reflects the process of failure. The value of the amplitude depends on the point of the AE sensor installation, including its orientation relative to the source of AE signal and distance to the source. The energy of AE signals is also an informative parameter for the diagnostics of large structures. This parameter quantitatively reflects the stages of the process of accelerated crack growth in the material of helicopter structural components. Due to a significant influence of mechanical noises during the tests, the total $\mathrm{AE}$ is informative only in the case of additional filtration. This process is rather time consuming and requires the development and application of a special program for the processing of recorded signals.

The analysis of fatigue damage kinetics was carried out in several stages: for groups of bolts and for characteristic structure loading intervals.

Stage 1. Range of load cycle numbers: 1 - 48000 cycles The analysis was carried out for the cases of crack initiation and propagation up to the complete failure of bolts No. 19-1, No. 18-1, No. 19-2, No. 18-2 as well as for the case of crack initiation and propagation in the material of bolt No. 21 (the bolt did not fracture).

The results of the AE data analysis in the range of 1 to 9812 serve as evidence of the processes of crack initiation in the material of helicopter structural components, for example, a crack in bolt No. 19-1 initiated in $900 . . .1100$ load cycles, when the amplitude of AE signals increased up to $85 \mathrm{~dB}$ for the first time during the tests. Additionally, sequential signals with the specified amplitude were recorded, which is indicative of the initiation of several nuclei at the micro-level (Fig. 6). Then, in the interval of 2200...3500 cycles, the changes in the AE signal amplitude and intensity pointed to the subsequent discrete growth of the crack.

The behaviour of total AE signals also confirmed fatigue crack initiation in 900-1100 load cycles (Fig. 7).

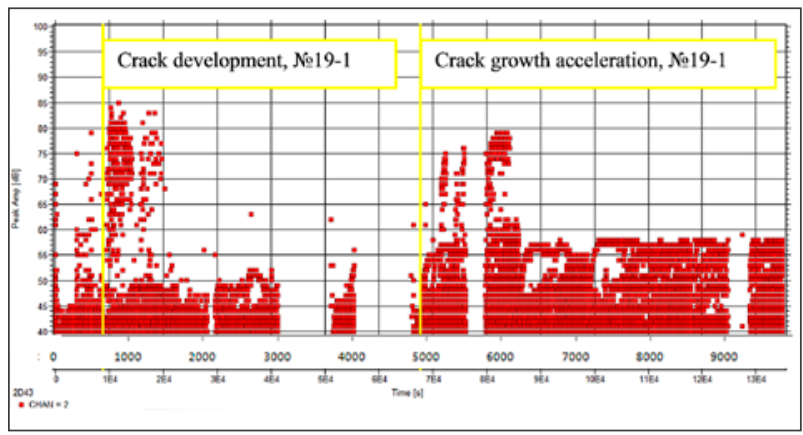

Fig. 6. Time dependent behaviour of amplitude of AE signals recorded in the interval of 1-9812 load cycles 


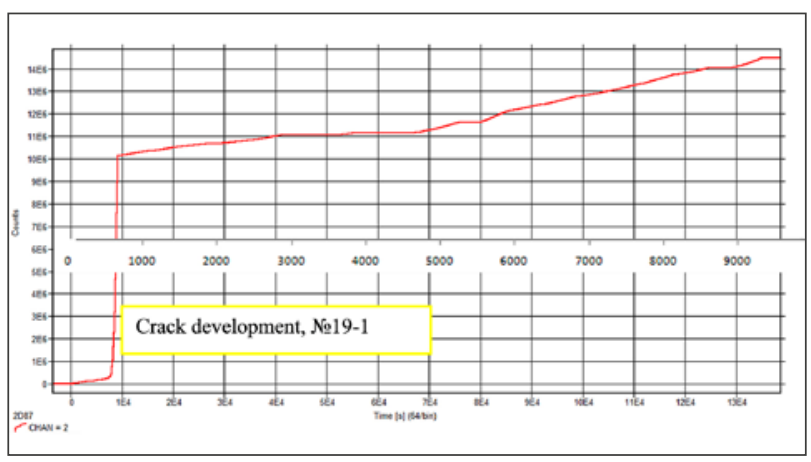

Fig. 7. Time dependent behaviour of total AE signals recorded in the interval of 1-9812 load cycles

During subsequent tests in the intervals from $3500-$ 3700 to $4200-4600$ cycles, an accelerated growth of the fatigue crack was detected (presumably, bolt No. 19-1). Subsequently, the crack was propagating discretely - retarded growth was followed by accelerated propagation.

Critical dimensions that were reached by the crack at the moment bolts No. 19-1 and No. 18-1 fractured were detected by all $\mathrm{AE}$ sensors, which reflects the corresponding change of total AE signals (Fig. 8).

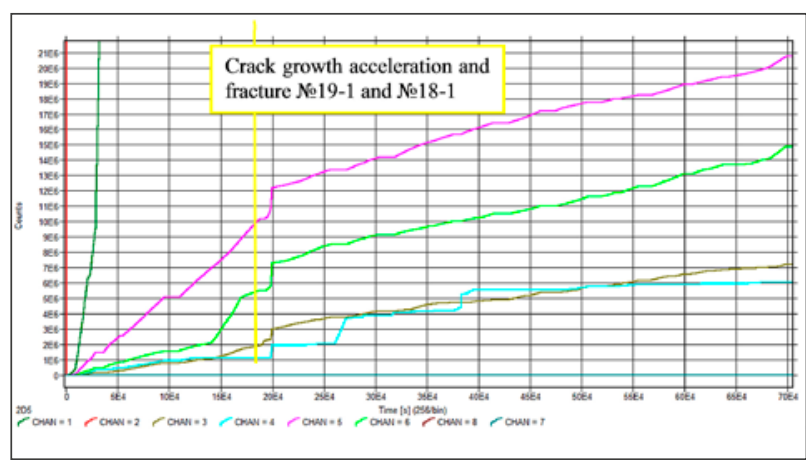

Fig. 8. Time dependent behaviour of total AE signals recorded in the interval of 9812-48000 load cycles

At the moment of failure, some increased amplitude signals - in a range from 85 to $100 \mathrm{~dB}$, on channels 4 , 5 and 6 respectively, were recorded. Similar results were subsequently received for bolts No. 19-2 and No. 18-2 installed instead of the failed bolts No. 19-1 and No. 18-1 (in 48000 load cycles) (Fig. 9).

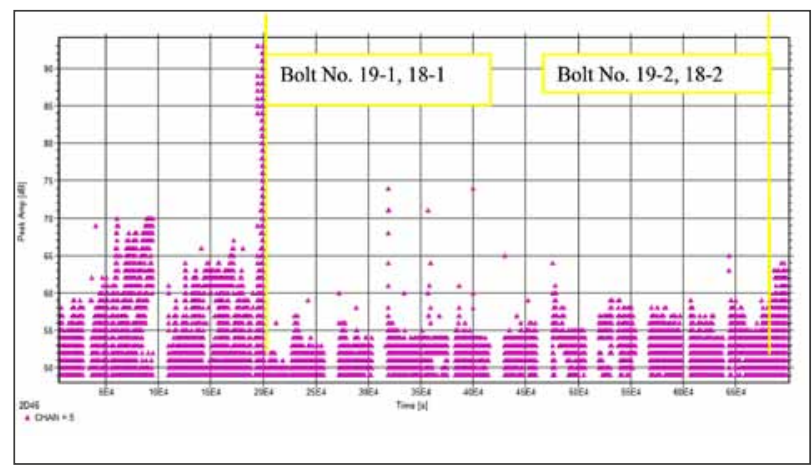

Fig. 9. Time dependent behaviour of amplitude of AE signals recorded in the interval of 9812-48000 load cycles
The intensity of AE signals in this particular case also quantitatively characterizes the stages of accelerated crack growth in the material of bolts No. 19-1, 19-2, 181, and 18-2 (Fig. 10).

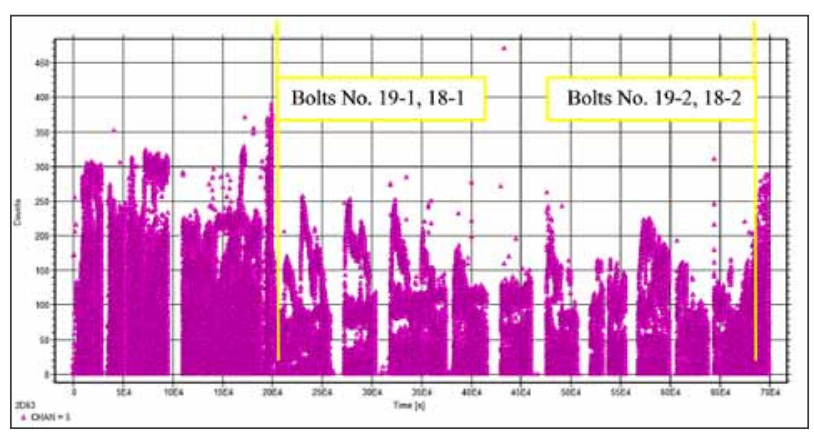

Fig. 10. Time dependent behaviour of intensity of AE signals recorded in the interval of 9812-48000 load cycles

\section{Stage 2. Range of load cycle numbers: 51000-108958 cycles}

The analysis was carried out for the cases of crack initiation and propagation up to the complete fracture of bolts No. 14 , No. 15, No. 19-3, No. 18-3 as well as for the case of crack initiation and propagation in the material of bolt No. 13 (the bolt did not fracture).

At this point, it is possible to confirm the informational content of the AE signal amplitude, which quantitatively reflects the presence of the stages of crack propagation in the material of helicopter structural components. For example, the amplitudes of AE signals emerging due to the critical growth of the crack along with the fracture of bolt No. 14 were $60-63 \mathrm{~dB}$, as recorded on channel 2, and 65-68 dB, as recorded on channel 1 (Fig. 11). The amplitudes of AE signals initiated by the propagating crack in the material of bolt No. 19-3 reach $80-83 \mathrm{~dB}$ on channel 2 and $70 \mathrm{~dB}$ for the case of recording on channel 1 .

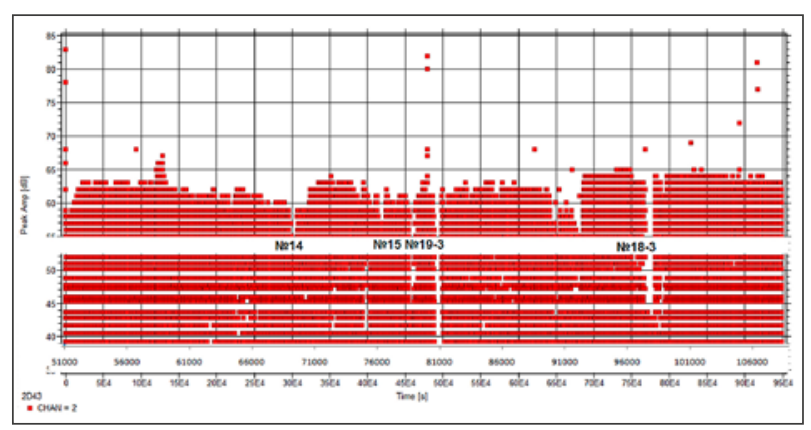

Fig. 11. Time dependent behaviour of amplitude of AE signals recorded in the interval of 51000-108958 cycles

The energy of AE signals also quantitatively reflects the process of fracture and serves as one of the criteria for evaluating fatigue damage in the material of bolts. The highest energy was detected at the moment of fracture of bolt No. 19-3 on channel 2 (Fig. 12). 


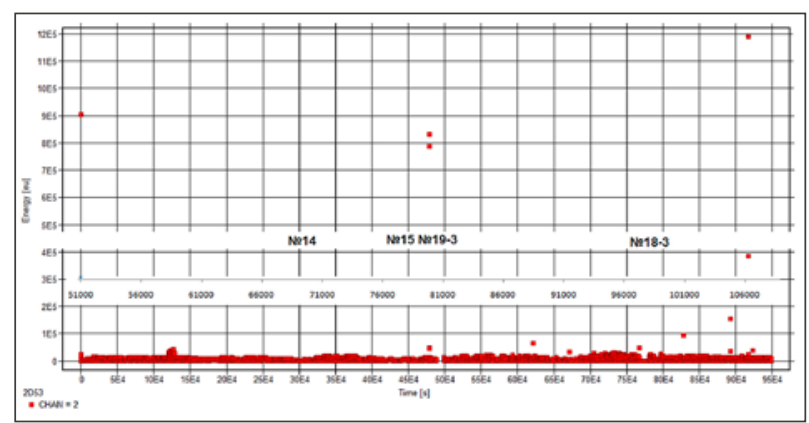

Fig. 12. Time dependent behaviour of energy of AE signals recorded in the interval of 51000-108958 cycles

The expanded time curve of the AE signal energy shows the moments of fracture of all bolts for both channels of the AE device (Fig. 13). It was also found that energy characterizes the accelerated growth of cracks in the bolt material.

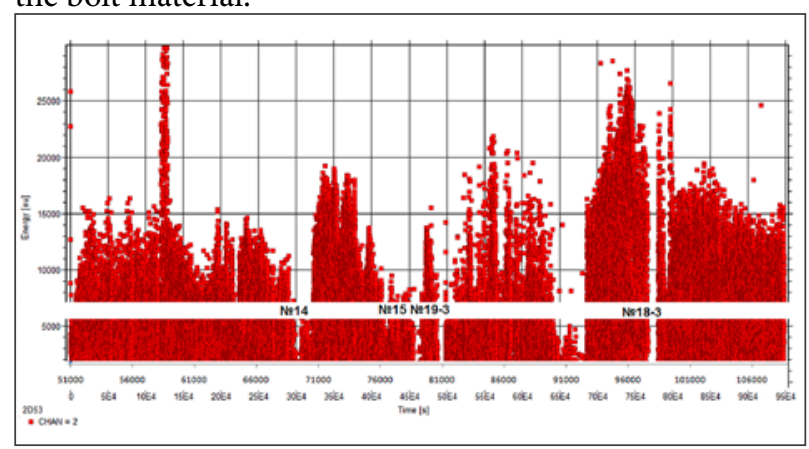

Fig. 13. Time dependent expanded energy curve of AE signals recorded in the interval of 51000-108958 cycles

The total energy parameter is also informative in terms of evaluating damage by using the AE method.

It should be noted that the AE signal intensity also quite reliably reflects the kinetics of fatigue damage and can be used as a diagnostic parameter for the evaluation of the helicopter structure damageability during bench tests.

The total AE signals depend considerably on the accepted discrimination threshold. and, in addition to that, their processing, as specified above, requires the development of a special algorithm and a program.

\section{General characteristics of the results of a fractographic analysis of bolt material surfaces}

On the basis of the fractographic analysis that we carried out, it was found that the propagation of fractures in the bolt material is characterized by the formation of lowcycle fatigue damage mesolines, the distance between which increases in a general case, which characterizes the acceleration of the crack growth rate as the crack length increases (fatigue damage areas). In all cases, the fracture has a multinuclear nature (Fig. 14). The material of bolts contains inclusions (Fig. 15).
At the same time the failure of bolts has a complex nature due to the influence of additional factors:

- cracks initiate and grow simultaneously in several bolts, leading to the redistribution of load among them during the tests, which is reflected in the mechanism of crack propagation;

- after periodic retightening of bolts during the tests (some bolts were retightened up to three times), the redistribution of stresses causes changes in the nature of fatigue mesoline propagation their obvious transition from a small to a larger size along with the propagation of damage was not observed.

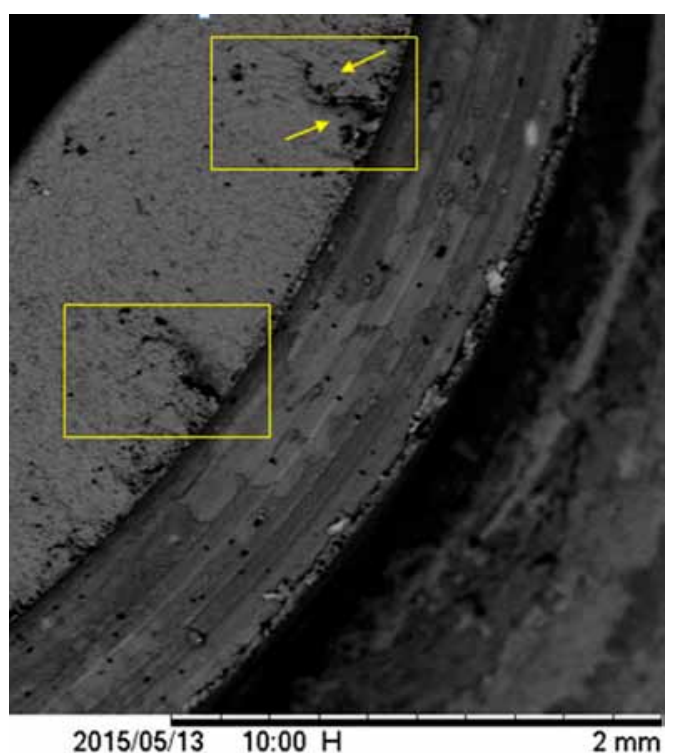

Fig. 14. Nucleus area

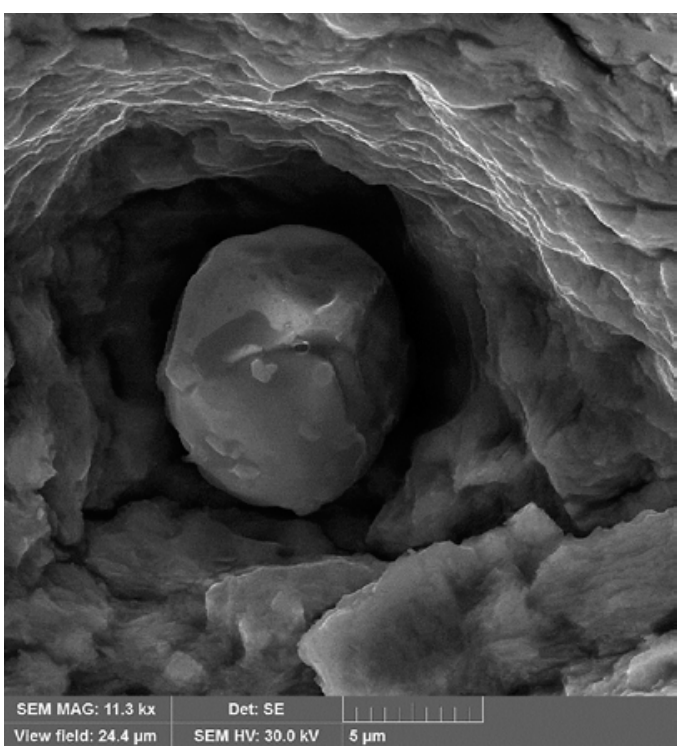

Fig. 15. Inclusion 


\section{Conclusions}

The helicopter fuselage and tail boom joint bolt fatigue damage diagnostics with fault localization were performed during bench tests based on AE method. Bolt fracture was predicted to at least 26 to 44 flight hours before the actual destruction. The micro crack origin intervals were identified using AE parameters and the bolt bearing capacity after the occurrence of the damage reached 96\% Fractographic analysis of fatigue relief confirmed the AE measurement results.

\section{References}

Aviatest. 2014. Programma sertifikatsionnykh ispytaniy na ustalost' khvostovoy balki kilya vertoleta. Aviatest LNK.

Lingelli, A. F. (Ed.). 2009. Fatigue crack growth: mechanics, behavior and prediction. New York: Nova Science Publishers Inc.. $264 \mathrm{p}$.

Paramonov, Y. M. 2009. Aeroplane structure and strength analysis. Part 1. Riga: RTU. 121 p.
Shanyavskiy, A. A. 2003. Bezopasnoe ustalostnoe razrushenie aviatsionnykh konstruktsiy. Sinergetika $v$ inzhenernykh prilozheniyakh. Ufa: Monografiya. $802 \mathrm{~s}$.

Urbahs, A.; Carjova, K.; Feerjov, J.; Stelpa, I. 2015. Development of theoretical model for aircraft structural health monitoring by acoustic emission method, in Mechanika 2015: Proceedings of the $20^{\text {th }}$ International Conference, $23-$ 24 April 2015, Kaunas, Lithuania. Kaunas: Kaunas University of Technology, 262-267.

Urbahs, A.; Shanyavskiy, A.; Banovs, M.; Carjova, K. 2012. Evaluation of an acoustic emission criterion of under surface fatigue cracks development mechanism in metals, in Transport Means 2012: Proceedings of the $16^{\text {th }}$ International Conference, 25-26 October 2012, Kaunas, Lithuania. Kaunas: Technologija, 131-134.

Vallen, H. 2006. Acoustic emission testing fundamentals, equipment, applications. Informative booklets for non-destructive testing. NDT compact and understable. Wuppertal, Germany: Castell Publication Inc. 